\title{
A prospective randomized trial comparing completion technique of fissures for lobectomy: Stapler versus precision dissection and sealant
}

\author{
Andrea Droghetti, MD, ${ }^{a}$ Andrea Schiavini, MD, ${ }^{a}$ Piergiorgio Muriana, MD, ${ }^{a}$ Anna Folloni, MD, ${ }^{b}$ Mauro Picarone, MD, \\ Cinzia Bonadiman, MD, ${ }^{a}$ Carlo Sturani, MD, ${ }^{c}$ Rolando Paladini, MD, ${ }^{b}$ and Giovanni Muriana, MD ${ }^{\mathrm{a}}$
}

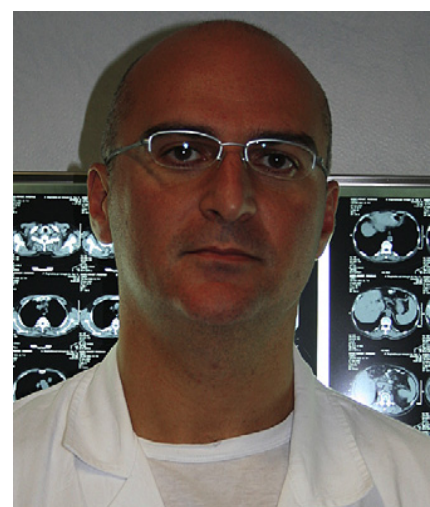

Dr Droghetti
Objective: Alveolar air leaks are common after pulmonary resection, often prolonging hospitalization and increasing surgical morbidity and costs. Air leakages result from lung tissue traumatized by the dissection of fissures. This randomized and controlled trial evaluates 2 different surgical techniques for the completion of interlobar fissures during pulmonary lobectomy to establish which is superior in preventing air leakage.

Methods: There were 20 patients in each of the 2 groups: Electrocautery was used for precision dissection and collagen patches were coated with human fibrinogen and thrombin (TachoSil, Nycomed, Vienna, Austria) for aerostasis in the electrocautery and sealant group (ES), and the approved routine surgical procedure with staplers was used in the stapler group (ST).

Results: Statistically significant reductions of air leakage were found in the ES group in the overall incidence of air leaks ( $50 \%$ vs $95 \%, P=.0001$ ), duration of air leaks (1.7 days vs 4.5 days, $P=.003$ ), and procedure costs (425 euros vs 630.5 euros, $P=.0001)$. There were no complications related to the use of the patches, and a significantly lower incidence of dead pleural space was observed in the ES group (5\% vs $40 \%$, $P=.020)$.

Conclusion: The use of electrocautery dissection and collagen patches coated with human fibrinogen and thrombin (TachoSil, Nycomed, Vienna, Austria) for aerostasis to complete interlobar fissures seems to be safe and effective in reducing alveolar air leaks and procedure costs. Although this pilot study showed advantages in terms of hospitalization and cost benefits, further multicentric studies are required to clarify that these differences are statistically significant.

$\mathrm{P}$ ulmonary lobectomy, performed by the division of the parenchyma through scission of the fissures, remains the standard therapeutic option in most patients with early-stage non-small cell lung cancer. Persistent alveolar air leaks, the most common complication after major pulmonary resection with an incidence of $3 \%$ to $25 \%$, occur more frequently when interlobar fissures are incomplete. Persistent alveolar air leaks have negative consequences on morbidity (empyema, deep vein thrombosis, and respiratory infections), culminating in increased hospitalization with negative economic effects and delays of adjuvant treatment. ${ }^{1-10}$ Most air leaks result from dissection of the fissures as demonstrated by the intraoperative air leaks exhibited by the traumatized lung tissue. Surgical staplers are widely used to complete fissures, usually providing reliable hemostasis but without obtaining an airtight closure for parenchymal tears at lung reexpansion under ventilation. ${ }^{1,2}$

We designed a randomized prospective controlled study to compare 2 different techniques to complete interlobar fissures during pulmonary lobectomy. Forty patients were enrolled and randomly assigned to 1 of the 2 procedures. In the electrocautery and sealant group (ES), electrocautery was used for precision dissection (a technique that was initially developed by Perelman ${ }^{11}$ ), and a collagen patch coated 


\section{Abbreviations and Acronyms \\ ES = electrocautery and sealant group \\ $\mathrm{ST}=$ stapler group \\ $\mathrm{AAL}=$ alveolar air leak}

with human fibrinogen and thrombin (TachoSil) was applied for aerostasis. In the stapler group (ST) approved routine surgical procedure with staplers was performed.

The trial was conducted according to the ethical principles of the Declaration of Helsinki and in accordance with local requirements and good clinical practice. This document was written according to the International Conference on Harmonisation E9 (Statistical Principles for Clinical Trials) and E3 (Structure and Content of Clinical Study Reports) guidelines of the European Agency for the Evaluation of Medicinal Products.

\section{Materials and Methods Study Objectives}

This randomized, prospective, controlled parallel-group designed trial compares 2 different techniques for completion of interlobar fissures during pulmonary lobectomy. The patients involved were assigned to 2 groups: the ES group (20 patients), in which electrocautery was used for precision dissection and a collagen patch was coated with human fibrinogen and thrombin (TachoSil) was applied for aerostasis, and the ST group (20 patients), in which an approved routine surgical procedure with staplers was carried out. This is a pilot study, and no attempts have been made to calculate a sample size to provide statistical power sufficient for confident evaluation of the result.

The first goal was to assess the percentage of demonstrated intraoperative alveolar air leak effectively sealed after application of the patch (TachoSil) in ES and to compare the proportion of patients in the experimental and control groups who were free of air leaks throughout hospitalization.

The second goal was to compare the experimental group with a control group in terms of the postoperative day that the last air leak was observed, the moment of chest tube removal, and the length of hospitalization. Other aspects that were analyzed were the costs of the procedure and hospitalization, and the safety of the experimental procedure in comparison with standard procedure by surveillance of the incidence and severity of complications.

\section{Patient Selection}

The study was performed at Carlo Poma Hospital, Mantova, Italy, during a period of 11 months (May of 2006 to April of 2007). Patients with early-stage non-small cell lung cancer who were scheduled for elective pulmonary lobectomy were eligible for inclusion in the study. The purpose of the study and potential risks and benefits of the procedure were explained to all patients, who were required to give signed informed consent before entering the trial.

During surgery, patients were deemed ineligible for further participation if the surgical treatment was completed by a video-assisted approach; if they underwent pneumonectomy, sleeve resection, or bronchoplasty; if they had an inoperable disease; or if other sealant materials were used.

At thoracotomy, fissures were defined according to Craig's classification: grade 1, complete fissure with entirely separate lobes; grade 2, complete visceral cleft but parenchymal fusion at the base of the fissure; grade 3, visceral cleft evident for part of the fissure; grade 4, complete fusion of the lobes with no evident fissural line. ${ }^{12}$ Only patients with fissures in grades 3 and 4 were included in the study.

\section{Randomization}

Forty patients were randomized into 2 groups of 20 . Randomization was performed intraoperatively using closed envelopes containing notes reading either "ES" for electrocautery and sealant or "ST" for conventional treatment with staplers. The groups were matched for sex, age, risk factors, duration of surgery, length of fissures, and type of lobectomy (Table 1).

\section{Surgical Techniques}

Standard lobectomy was performed via lateral or posterolateral thoracotomy according to the surgeon's preference.

\section{Electrocautery and Sealant Group}

Precision dissection of fissures, consisting of a gradual and accurate separation of lung tissue through punctate electrocoagulation and isolated application of ligatures, was conducted with the use of magnifying lenses. During the procedure, the assistant retracted the tissue of the lobe being removed as the surgeon held back the lung tissue of the other lobe with the forceps. In the other hand the surgeon held a forceps for electrocoagulation with which he/she gripped 1 small portion of tissue at a time and then coagulated it. Visible branches of the bronchial tree and larger vascular branches were ligated rather than coagulated. After completion of fissures by electrocautery, parenchymal leakage was evaluated by submersion of the resection site in saline and reventilation of the lung, applying a peak pressure of 25 to $35 \mathrm{~cm} \mathrm{H}_{2} \mathrm{O}$. Leakage was graded according to Macchiarini's scale as 0 (no leakage), 1 (single bubbles), 2 (stream of bubbles), or 3 (coalescent bubbles). ${ }^{13}$ No other procedures were performed for all grades of leakage. The only aerostatic procedure performed in this group was the application of a sterile, ready to use, completely absorbable $9.5 \times 4.8 \times 0.5-\mathrm{cm}^{3}$ collagen patch coated with human fibrinogen and thrombin (TachoSil). After premoistening with physiologic saline, with the lung moderately ventilated, the patch was easily applied by pressing it to the pulmonary surface at least $1 \mathrm{~cm}$ beyond the margin of dissection (Figures 1 and 2).

\section{Stapler Group}

After complete separation of fissures by routine procedure with staplers, the lung was ventilated to a pressure of 25 to $35 \mathrm{~cm} \mathrm{H}_{2} \mathrm{O}$ to graduate air leaks according to Macchiarini's scale. ${ }^{13}$ Patients with grade 3 air leakage underwent further standard techniques to reduce all leaks, including restapling, suturing, or tissue grafting, followed by repeat submersion testing until the grade of the air leaks was reduced to grade 2 or less.

\section{After Surgery}

Afterward, all patients received single drainage $(28 \mathrm{~F}$ or $32 \mathrm{~F})$ and were connected to a Pleur-evac system (Pleur-evac A-7000-08LF, Genzyme Surgical Products Corporation, Fall River, Massachussets, 
TABLE 1. Demographics and baseline characteristics

\begin{tabular}{|c|c|c|c|c|}
\hline \multirow[b]{2}{*}{ Variables } & \multicolumn{2}{|c|}{ Procedure } & \multirow[b]{2}{*}{ Total $(\mathrm{N}=\mathbf{4 0})$} & \multirow[b]{2}{*}{$P$ between procedures (applied test) } \\
\hline & ST $(\mathbf{N}=20)$ & ES $(N=20)$ & & \\
\hline Sex Male & $11(55 \%)$ & $18(90 \%)$ & $29(72 \%)$ & $P\left(\chi^{2}\right)=.013$ \\
\hline Female & $9(45 \%)$ & $2(10 \%)$ & $11(28 \%)$ & \\
\hline Age (y) Mean & 68.5 & 70.2 & 69.4 & \\
\hline SD & 8.1 & 4.5 & 6.5 & $P($ unpaired $t$ test $)=.431$ \\
\hline Maximum & 81.0 & 81.0 & 81.0 & \\
\hline Median & 68.0 & 70.0 & 69.0 & \\
\hline Minimum & 52.0 & 59.0 & 52.0 & \\
\hline Risk factors Smoke & $16(80 \%)$ & $16(80 \%)$ & $32(80 \%)$ & $P\left(\chi^{2}\right)=1.000$ \\
\hline Emphysema & $5(25 \%)$ & $6(30 \%)$ & $11(28 \%)$ & $P\left(\chi^{2}\right)=.723$ \\
\hline Job & $1(5 \%)$ & $3(15 \%)$ & $4(10 \%)$ & $P($ Fisher exact test $)=.605$ \\
\hline Duration of surgery (min) Mean & 189.8 & 188.5 & 189.1 & $P$ (unpaired $t$ test $)=.955$ \\
\hline SD & 66.4 & 73.9 & 69.4 & \\
\hline Maximum & 320.0 & 375.0 & 375.0 & \\
\hline Median & 185.0 & 180.0 & 180.0 & \\
\hline Minimum & 80.0 & 80.0 & 80.0 & \\
\hline Length of fissures (mm) Mean & 96.3 & 128.3 & 112.3 & $P$ (Wilcoxon's 2-sample \\
\hline SD & 49.1 & 46.5 & 49.9 & test) $=.084$ \\
\hline Maximum & 195.0 & 190.0 & 195.0 & \\
\hline Median & 105.0 & 95.0 & 95.0 & \\
\hline Minimum & 80.0 & 95.0 & 20.0 & \\
\hline Operated lung right & $15(75 \%)$ & $10(50 \%)$ & $25(63 \%)$ & $P\left(\chi^{2}\right)=.103$ \\
\hline Left & $5(25 \%)$ & $10(50 \%)$ & $15(37 \%)$ & \\
\hline Operated lung/lobe right lower & $4(27 \%)$ & $1(10 \%)$ & $5(20 \%)$ & \\
\hline Lower + Medium & $1(7 \%)$ & $3(30 \%)$ & $4(16 \%)$ & \\
\hline Medium & $1(7 \%)$ & $1(10 \%)$ & $2(8 \%)$ & $P($ Fisher exact test $)=.117$ \\
\hline Upper & $9(60 \%)$ & $3(30 \%)$ & $12(48 \%)$ & \\
\hline Upper + Medium & $0(0 \%)$ & $2(20 \%)$ & $2(8 \%)$ & \\
\hline Total & 15 & 10 & 25 & \\
\hline Left lower & $2(40 \%)$ & $3(30 \%)$ & $5(33 \%)$ & \\
\hline Upper & $3(60 \%)$ & $7(70 \%)$ & $10(67 \%)$ & $P($ Fisher exact test $)=1.000$ \\
\hline \multirow[t]{2}{*}{ Total } & 5 & 10 & 15 & \\
\hline & \multicolumn{3}{|c|}{ Overall lobectomy comparison by lung side } & $\begin{array}{l}P \text { (Cochran-Mantel-Haenszel } \\
\text { test })=.140\end{array}$ \\
\hline
\end{tabular}

USA) with a 7-column air leak meter. All patients initially had their chest tube placed on $-20 \mathrm{~cm} \mathrm{H}_{2} \mathrm{O}$ suction in the operating room, in an attempt to establish initial reexpansion of the lung, and underwent chest radiography after extubation. Patients were disconnected from suction for transfer to the recovery unit. On arrival in the recovery room, patients were placed back on $-20 \mathrm{~cm} \mathrm{H}_{2} \mathrm{O}$ suction. On the basis of results from previous randomized trials, chest tubes were always placed to water seal 48 hours after surgery. $3,14,15$

Air leaks were catalogued twice daily according to the classification reported by Cerfolio and colleagues ${ }^{3}$ as expiratory, forced expiratory, inspiratory, or continuous and were scored from 1 to 7 by the Pleur-evac air leak meter (Figure 3). To remove the tube, the volume of drained fluids was required to be less than $100 \mathrm{~mL}$ during the preceding 24-hour period and all air leaks resolved.

The length of stapled tissue in the ST group and dissected parenchyma in the ES group was indirectly calculated by counting the number of staplers and TachoSil patches used. The calculated lengths were then correlated to the duration of air leaks and the moment of chest tube removal.
The estimated daily cost of hospitalization per patient was 800 euros. For each patient assigned to the ST group, 1 device complete with recharge was used, and additional recharges were supplied when necessary. The cost of each stapler was 355 euros for the device with the first recharge and 190 euros for each additional recharge. In the ES procedure, the cost of each patch was 315 euros.

\section{Follow-up}

One and 3 months after surgery, the treated patients underwent a clinical examination and chest radiography. A chest computed tomography was performed after 6 months.

\section{Statistical Methods}

All of the statistical procedures described were performed with the SAS package (SAS, Version 9.1.2; SAS Institute Inc, Cary, NC). The significance level was set to $5 \%(\alpha=0.05)$ for all efficacy and safety parameters. The 2 procedures were compared by the unpaired $t$ test or Wilcoxon's 2-sample test applied to discrete or continuous data, and by the chi-square test or Fisher exact 


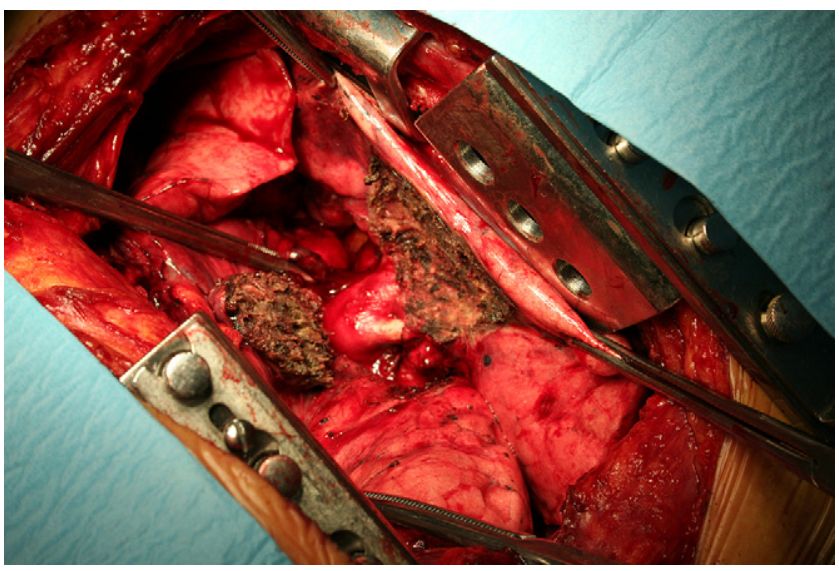

Figure 1. Fissure after dissection with electrocautery.

test when appropriate, applied to dichotomous or categoric data. Stratified analysis of categoric data was performed with the Cochran-Mantel-Haenszel procedure. The normality of data distribution was assessed by the Shapiro-Wilk test.

\section{Results}

During the 11-month period, 40 patients (29 male [72\%] and 11 female [28\%]) ranging in age from 52 to 81 years (mean age 69.4 years) were included in the study and randomly assigned to each of the 2 groups. The 20 patients assigned to the ST group underwent the approved routine surgical procedure with staplers, and the 20 patients assigned to the ES group were treated with electrocautery for precision dissection and a collagen patch coated with human fibrinogen and thrombin (TachoSil) was applied for aerostasis. The demographics and baseline characteristics of the 2 groups were similar, except for a significant difference in gender distribution (ST: male $55 \%$, female $45 \%$; ES: male $90 \%$, female $10 \% ; P=.013$ ).

The average length of fissures in the ES group was 128.3 $\mathrm{mm}$ (range 95-190 $\mathrm{mm}$ ), and the average length of stapled

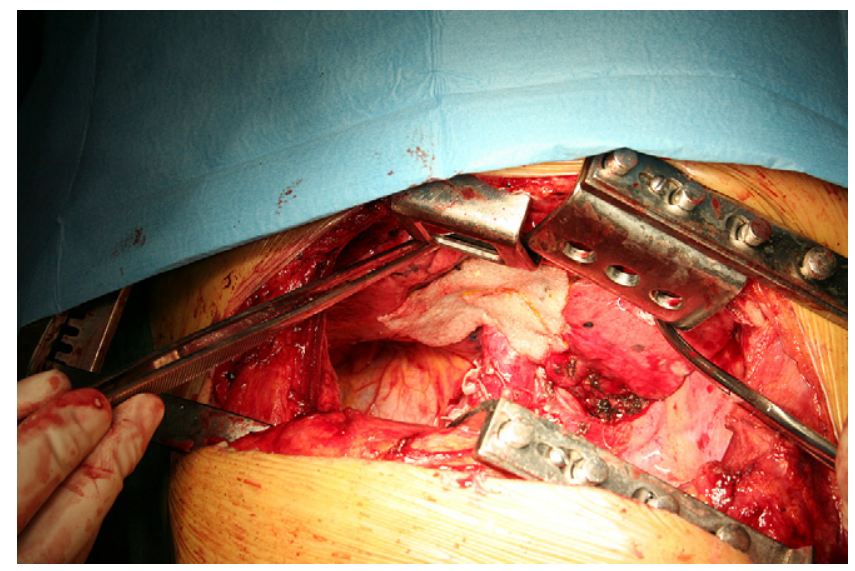

Figure 2. Fissure after positioning of TachoSil Nycomed, Vienna, Austria.

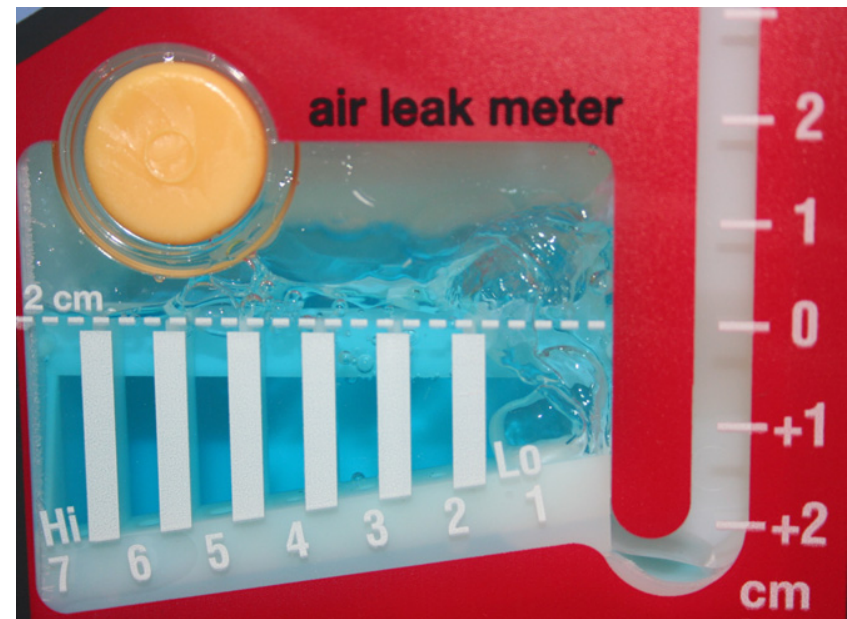

Figure 3. Pleur-evac A-7000-08LF, Genzyme Surgical Products Corporation, Fall River, Massachussets USA with air leak meter.

parenchyma in the ST was $96.3 \mathrm{~mm}$ (range 80-195 $\mathrm{mm}$ ), with no statistically significant difference ( $P$ [Wilcoxon's 2-sample test $]=.084)$. There was no significant difference in the length of time required to perform the 2 techniques (Table 1).

\section{Air Leaks}

There was a $100 \%$ incidence of intraoperative air leaks in the ES group after electrocautery dissection and before application of TachoSil, which was higher than the incidence of $90 \%$ among patients of the ST group. The distribution of air leaks in the ES group, according to Macchiarini's scale, was as follows: 4 patients $(20 \%)$ with grade 1 air leaks, 9 patients $(45 \%)$ with grade 2 air leaks, and 7 patients (35\%) with grade 3 air leaks. In the ST group there were 4 patients $(20 \%)$ with grade 1 leaks and 14 patients $(70 \%)$ with grade 2 air leaks, whereas there were no grade 3 air leaks.

Because the difference in distribution of the scores of Macchiarini's scale was significant $(P=.028), 2$ further tests were performed by grouping the severity scores as follows: first test, scores 0 to 1 versus scores 2 to 3 ; second test, scores 0 to 2 versus score 3 . The results of the second test show that the incidence of score 3 was significantly higher in the ES group $(P=.008)$ (Table 2$)$. The significant difference in air leakage volume observed intraoperatively $(\mathrm{ES}>\mathrm{ST}$ ) was inverted after application of the patch and maintained for the entire postsurgical period (Figure 4). Postsurgery, the incidence in the ES group was $40 \%$ (8/20 patients), which was significantly lower than the $80 \%$ incidence of the ST group (16/20 patients) $(P=.010)$; this significant difference was confirmed during the period from day 0 to the end of hospitalization (ST 95\% vs ES 50\%, $P=.001$ ).

On postoperative day 1, air leakage was detected in 7 of 20 patients $(35 \%)$ in the ES group and 12 of 20 patients $(60 \%)$ in 
TABLE 2. Intraoperative air leaks

\begin{tabular}{|c|c|c|c|c|}
\hline \multirow[b]{2}{*}{ Variables } & \multicolumn{2}{|c|}{ Procedure } & \multirow[b]{2}{*}{ Total $(\mathrm{N}=40)$} & \multirow[b]{2}{*}{$P$ between procedures (applied test) } \\
\hline & ST $(N=20)$ & $E S(N=20)$ & & \\
\hline Scale of Macchiarini 0 & $2(10 \%)$ & $0(0 \%)$ & $2(5 \%)$ & $P$ (Wilcoxon's 2-sample test $)=.028$ \\
\hline (score) 1 & $4(20 \%)$ & $4(20 \%)$ & $8(20 \%)$ & \\
\hline 2 & $14(70 \%)$ & $9(45 \%)$ & $22(55 \%)$ & \\
\hline 3 & $0(0 \%)$ & $7(35 \%)$ & $8(20 \%)$ & \\
\hline Scale of Macchiarini $0-1$ & $6(30 \%)$ & $4(20 \%)$ & $10(25 \%)$ & $P\left(\chi^{2}\right)=.465$ \\
\hline (grouped scores) 2-3 & $14(70 \%)$ & $16(80 \%)$ & $30(75 \%)$ & \\
\hline Scale of Macchiarini $0-2$ & $20(100 \%)$ & $13(65 \%)$ & $33(83 \%)$ & $P($ Fisher exact test $)=.008$ \\
\hline (grouped scores) 3 & $0(0 \%)$ & $7(35 \%)$ & $7(17 \%)$ & \\
\hline Drainage 28 & $1(5 \%)$ & $2(10 \%)$ & $3(8 \%)$ & $P\left(\chi^{2}\right)=.548$ \\
\hline 32 & $19(95 \%)$ & $18(90 \%)$ & $37(92 \%)$ & \\
\hline
\end{tabular}

the ST group. On postoperative day 2, air leakage was detected in 4 of $20(20 \%)$ in the ES group and 7 of 20 patients (35\%) in the ST groups. The incidence of air leakage in the first 48 hours was detected in 10 of 20 patients $(50 \%)$ and 19 of 20 patients $(95 \%)$ in the ES and ST groups, respectively $(P=.001)$. Persistent air leakage (for $>7$ days) was detected in 1 of 20 patients $(5 \%)$ and 3 of 20 patients $(15 \%)$ in the ES and ST groups, respectively $(P=.605)$. The mean duration of air leaks for the trial population was 1.7 days in the ES group, significantly shorter than the 3.7 days of the ST group $(P$ [Wilcoxon's 2-sample test $]=.005)$ (Figure 5). The mean duration of the last occurence of air leaks was significantly shorter in the ES group (mean 1.7 days, range 0-10 days) than in the ST group (mean 4.5 days, range $0-16$ days) ( $P$ [Wilcoxon's 2-sample test] $=.003$ ) (Figure 6). The severity of air leaks, assessed by grading with the Pleur-evac device, was significantly lower in the ES group, considering both the average severity ( 0.5 vs $1.3, P$ [Wilcoxon's 2 -sample test] $=$ $.004)$ and the maximum severity over the observation period (0.5 vs 1.5, $P$ [Wilcoxon's 2-sample test] $=.003)$.

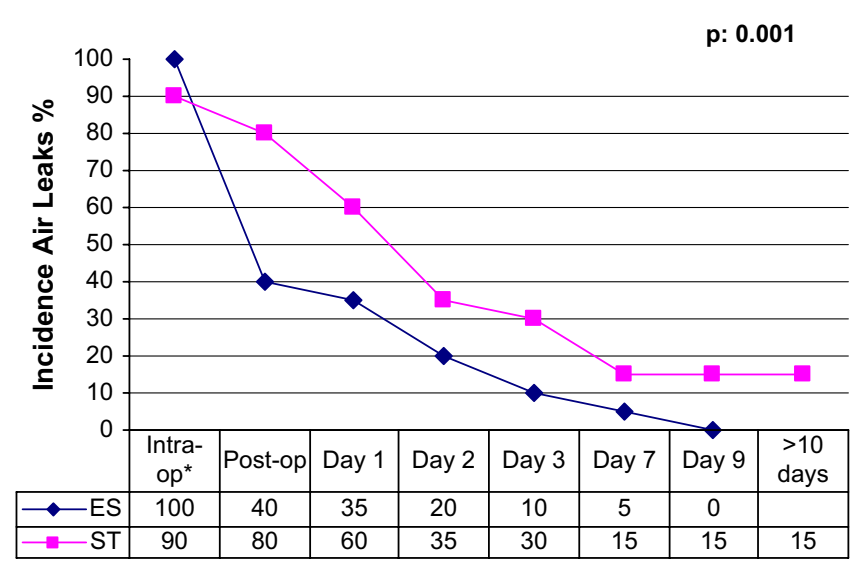

*Intra-operatory before application of Tachosil®

Figure 4. Efficacy parameters: incidence of air leaks.
We determined the duration of air leak per millimeter of stapled or dissected pulmonary parenchyma from the length of the fissures. The corrected air leak durations were significantly different at 0.059 days $/ \mathrm{mm}$ for the ST group and 0.015 days/mm for the ES group $(P<.001)$.

\section{Leak of Liquid}

For each patient, the cumulative and average leak of liquid during the observation period and the days with leaks were calculated. The results do not show any statistically significant difference between procedures. In the ES group, the daily drainage leak was $270 \mathrm{~mL}$ versus $234.7 \mathrm{~mL}$ in the ST group $(P=.053)$. The mean duration of liquid leaks $(>100$ $\mathrm{mL} / 24 \mathrm{~h}$ ) for the trial population was 7.1 in the ES group, which was shorter than the 8.4 days in the ST group ( $P$ [Wilcoxon's 2-sample test] $=.837$ ) (Figure 7).

\section{Chest Tube}

The ES group had a tube in place for a mean time of 7.6 days (range 4-13 days), whereas the mean time was 10.2 days (range 4-55 days) in the ST group. This difference ( $>48$ hours) was not statistically significant, probably because of the small sample size (Figure 8).

We determined the chest tube removal time per millimeter of stapled or dissected pulmonary parenchyma from the length of the fissures. The corrected chest tube times were also different between the 2 groups: 0.148 days $/ \mathrm{mm}$ stapled parenchyma in the ST group and 0.066 days $/ \mathrm{mm}$ dissected parenchyma in the ES group $(P=.047)$ (Figure 9).

\section{Complications}

The incidence of the overall complications was lower in the ES group, but the difference between procedures did not reach statistical significance. No adverse effects were observed intraoperatively or postoperatively regarding the use of TachoSil. No perioperative mortality was observed. No patient required a reoperation or blood transfusion. Transient 


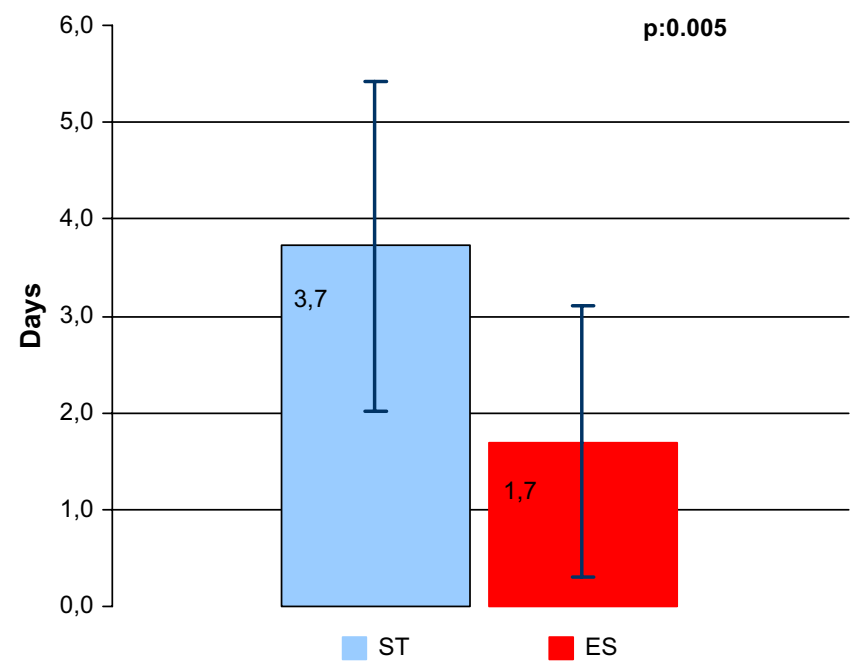

Figure 5. Mean values and $95 \%$ confidence interval (CI) of days with air leaks.

episodes of fever $\left(>38^{\circ} \mathrm{C}\right.$ ) were observed in 4 patients ( 3 in the ST group, 1 in the ES group), but all were resolved with empirical antibiotic therapy. Two patients, 1 from each group, experienced atrial fibrillation that necessitated pharmacologic cardioversion. One episode of left recurrent nerve palsy and 1 episode of chylothorax were the result of extensive lymphadenectomy. By extrapolating the incidence of dead pleural space, which may be considered the main postoperative complication, we observed that it was significantly lower in the ES group (ST 40\% vs ES 5\%; $P=.020$ ).

\section{Hospitalization}

The difference in mean hospitalization length of the 2 procedures did not achieve statistical significance; however, in the ES group

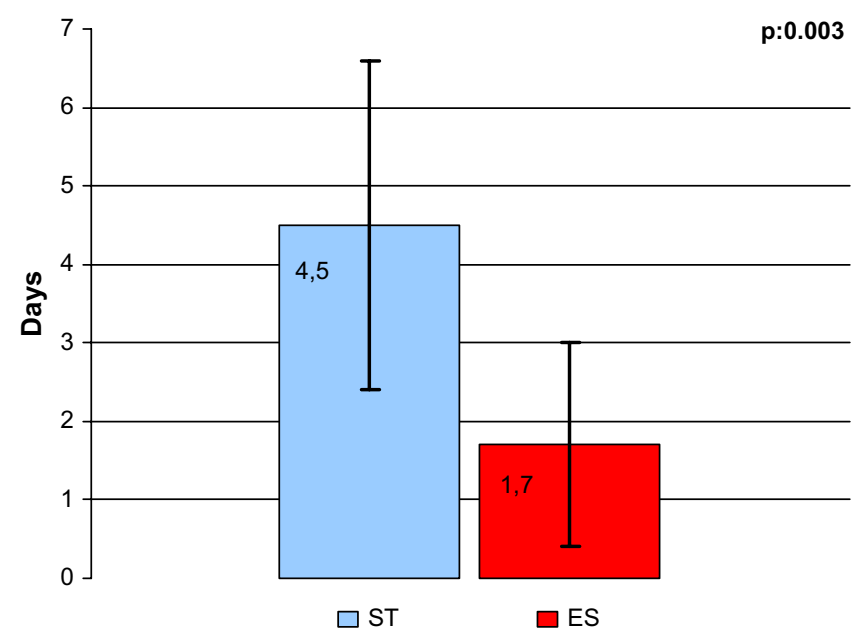

Figure 6. Mean values and $95 \% \mathrm{Cl}$ days to the last occurrence of air leaks. it was 11.0 days (range 9-17 days), which was shorter than the 14.3 days (range $8-57$ days) in the ST group (Figure 10).

\section{Cost Analysis}

The mean cost (euros) of the ST procedure was significantly higher than that of the ES procedure (630.5 euros for ST vs 425 euros for ES; $P=.001$ ). The mean cost of hospitalization, 11,440 euros (range 6400-45,600) for ST and 8760 for ES, was approximately 3000 euros lower for the experimental group; however, this difference was not statistically significant.

\section{Discussion}

Postoperative air leakage remains the major problem after lung resection. ${ }^{1,3,4}$ The routine use of surgical staplers does not result in adequate sealing in the majority of patients, ${ }^{2,16}$ which leads to prolonged chest tube drainage time, increasing the patient's risk of pleural infections, pulmonary embolism, respiratory distress, and associated pain, therefore prolonging hospital stay. ${ }^{3,13}$

Many procedures, such as the application of fibrin glue, ${ }^{17-19}$ synthetic sealant, ${ }^{20,21}$ and biodegradable sealant $^{22,23}$ reinforcement of pulmonary closure with various materials, ${ }^{24,25}$ and the use of laser, ${ }^{26,27}$ ultrasonic dissection, ${ }^{28}$ and autologous blood patch ${ }^{10}$ have been proposed to control and prevent air leaks (Table 3).

This trial was designed to compare 2 different fissure completion techniques for performing a major lung resection. The use of the TachoSil patch, clearly different from its application in previous studies, ${ }^{29,30}$ is only a part of the procedure that was carried out. All of the parameters of air leakage-incidence, mean duration, lasting, and severity-were statistically significant with lower values for the experimental group.

We agree with Stolz and colleagues ${ }^{16}$ that staplers have a greater capacity in preventing air leaks than manual

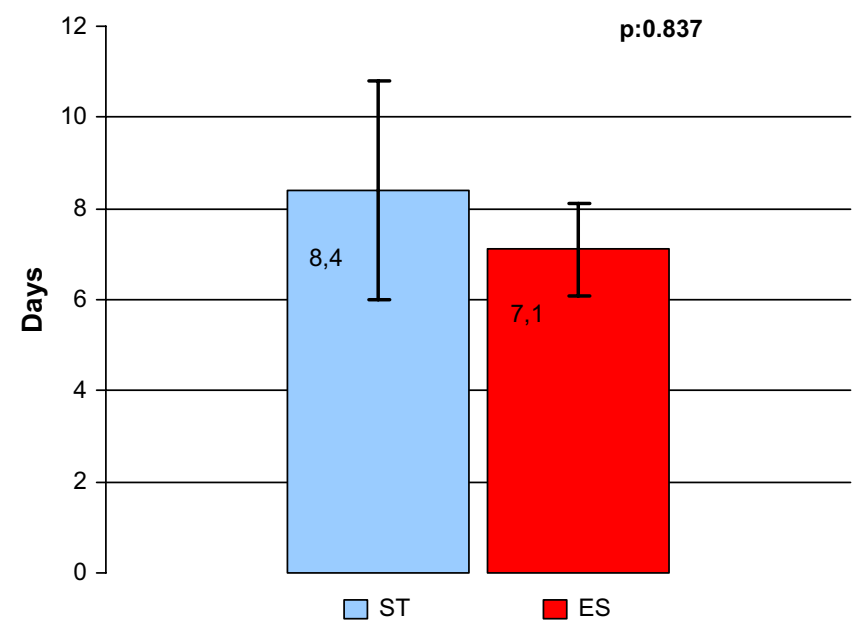

Figure 7. Mean values and $95 \% \mathrm{Cl}$ of days with liquid leaks. 


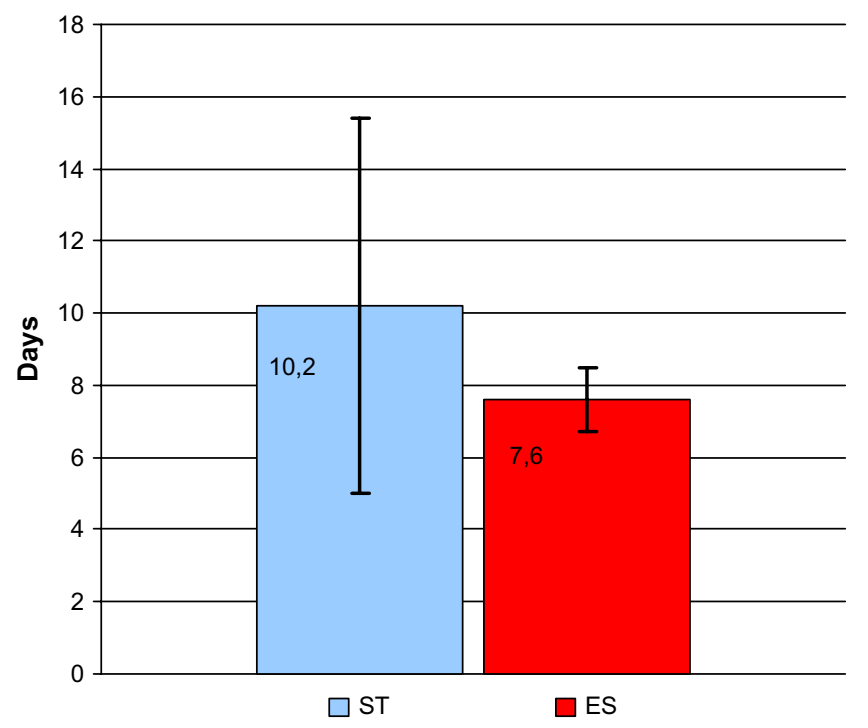

Figure 8. Mean values and $95 \% \mathrm{Cl}$ of time (days) to the drainage removal.

dissection alone. We observed a significantly greater incidence and severity of intraoperative air leaks in the ES group, but we demonstrated a relevant reduction of these on postoperative day 1 after application of TachoSil. This reduction of approximately $60 \%$ was maintained throughout hospitalization with an inversion of incidence between the 2 groups. The ES group showed a trend toward a reduction in the proportion of patients with leakage after more than 48 hours and more than 7 days, as well as a reduction in the mean leakage volumes at these times. The mean duration of the occuence of

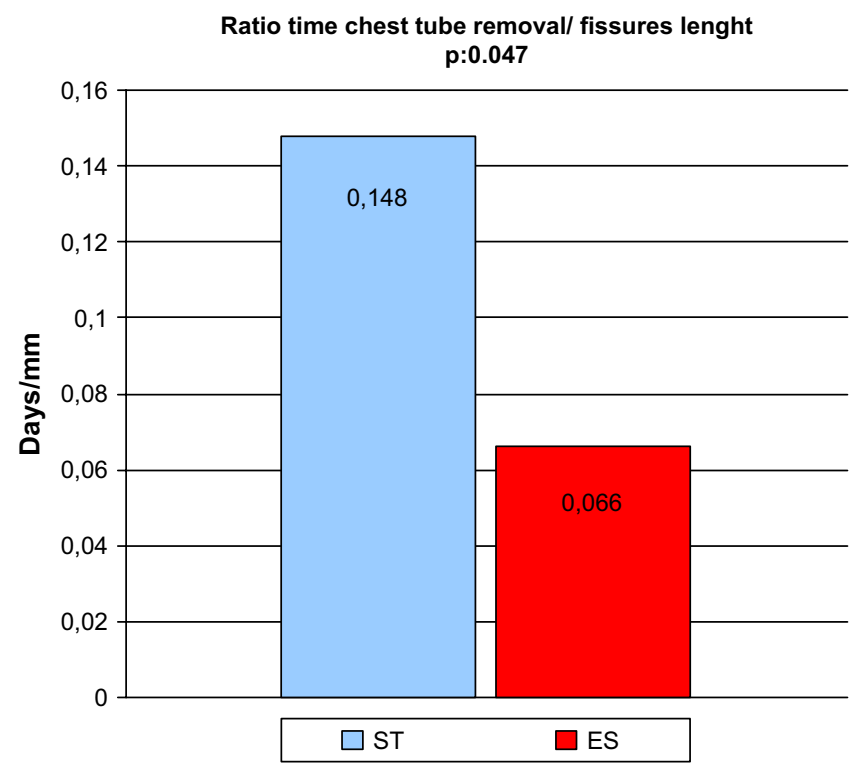

Figure 9. Ratio time chest tube removal/fissures length.

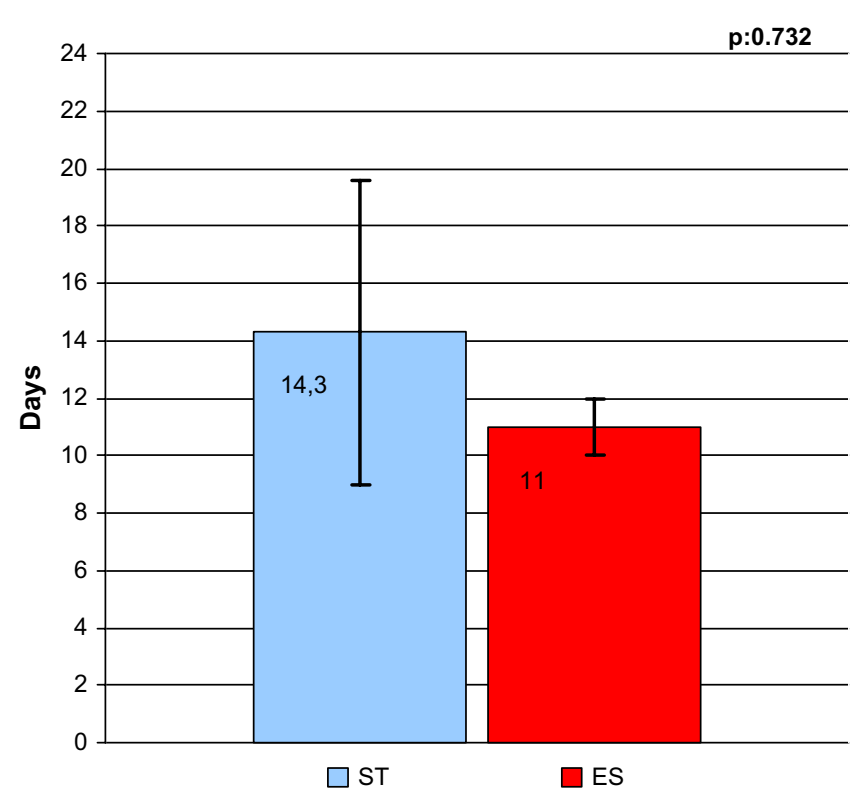

Figure 10. Mean values and $95 \% \mathrm{Cl}$ of hospitalization length (days).

air leaks was significantly shorter in the ES group (1.7 vs 4.5 days, $P=.003$ ), and the ratio between the time to the last occurrence of air leak and the length of scissure was also significantly smaller in the ES group ( 0.015 vs 0.059 days $/ \mathrm{mm}, P$ $<.001)$.

The multiple aspects of the better sealant results in the ES group and the ability of the regulated dissection to preserve as much pulmonary parenchyma as possible permit the residual lung to be bigger and maintain more elasticity than after being stapled with a better capacity to fill the thoracic cavity. This led to a minor incidence of complications such as dead pleural space in the ES group.

The benefits of TachoSil translated to a reduction of more than 48 hours in the mean time of chest drain removal and more than 3 days in hospitalization, although this trend did not reach statistical significance in our study because of the small size of the population from whom the results were drawn.

Inasmuch as patients must remain under clinical observation during chest drainage and tube removal is conditioned not only by the presence of air leaks but also by the liquid leaks, the period of hospitalization was not significantly reduced in the experimental group because the duration of liquid leaks was similar in the 2 groups. Although the incidence of dead pleural space was significantly lower in the ES group, the incidence of overall complications was also lower in the ES group, but the difference was not statistically significant.

\section{Conclusions}

Although this relatively small-scale study included a formal cost-saving analysis showing significant differences in the 
TABLE 3. Randomized studies of sealant in lung surgery

\begin{tabular}{|c|c|c|c|c|c|c|c|}
\hline Wong and Goldstraw ${ }^{17}$ & $\mathrm{FG}$ & Control: 33 & NA & 4 vs 5 & NA & 6 vs 6 & 9 vs 8 \\
\hline \multirow{2}{*}{$\begin{array}{l}\text { Fleisher and } \\
\text { colleagues }^{18}\end{array}$} & \multirow[t]{2}{*}{$\mathrm{FG}$} & Control: 14 & 79 vs 79 & 3.3 vs 3.2 & 7 vs 14 & 5.9 vs 6.1 & 11.5 vs 9.8 \\
\hline & & Experimental: 14 & NS & NS & NS & NS & NS \\
\hline $\begin{array}{c}\text { Macchiarini and } \\
\text { colleagues }^{13}\end{array}$ & SLS & Control: 11 & 81 vs 23 & 2.4 vs 1.9 & NA & 6.9 vs 6.1 & 14 vs 13 \\
\hline Porte and colleagues ${ }^{20}$ & SLS & Experimental: 59 & Significant & Significant & NS & NA & NS \\
\hline \multirow[t]{2}{*}{ Wain and colleagues ${ }^{21}$} & \multirow[t]{2}{*}{ SLS } & Control: 55 & 89 vs 61.5 & $52.3 \mathrm{~h}$ vs $30.9 \mathrm{~h}$ & 7 vs 2.5 & 4.5 vs 5.2 & 10.1 vs 7.5 \\
\hline & & Experimental: 117 & Significant & Significant & NS & NS & NS \\
\hline \multirow{2}{*}{$\begin{array}{l}\text { Anegg and } \\
\text { colleagues }^{29}\end{array}$} & \multirow[t]{2}{*}{ TachoSil } & Control: 77 & 38 vs 30 & NA & 32 vs 24 & 6.3 vs 5.1 & 4.9 vs 4.6 \\
\hline & & Experimental: 75 & NS & NA & NS & Significant & NS \\
\hline \multirow{2}{*}{$\begin{array}{l}\text { Droghetti and } \\
\text { colleagues } \\
\text { (present study) }\end{array}$} & TachoSil, & Control: 20 & 95 vs 50 & 3.7 vs 1.7 & 15 vs 5 & 10 vs 7 & 14.3 vs 11 \\
\hline & $\begin{array}{l}\text { Nycomed, } \\
\text { Vienna, } \\
\text { Austria }\end{array}$ & Experimental: 20 & Significant & Significant & NS & NS & NS \\
\hline
\end{tabular}

$A A L$, Alveolar air leak; $P A L$, persistent air leak; $F G$, fibrin gene; $S L S$, synthetic lung sealant; $N A$, not available; $N S$, not significant.

mean cost of the procedures, with ES costing less than ST (425 vs 630 euros, $P=.001$ ), and in the mean hospitalization cost, which was more than 2500 euros lower for the ES group, these did not reach a significant difference in our study. These results could be predictive of significant differences in chest tube removal, hospitalization, and costs in a larger population trial; however, further studies are necessary to investigate these issues.

We thank Dr Patrizio Sala for preparing the statistical model for analysis and elaborating the data, and Daniele Larcher, Dr Marco Nazzari, and Dr Anna Pierini for technical contribution. We are especially grateful for the help, support, and patient care provided by the nurses of the Thoracic Surgery Department of Carlo Poma Hospital.

\section{References}

1. Rice TW, Kirby TTJ. Prolonged air leak. Chest Surg Clin North Am. 1992;2:803-11.

2. Hood RM. Stapling techniques involving lung parenchyma. Surg Clin North Am. 1984;64:469-80.

3. Cerfolio RJ, Tummala RP, Holman WL, Zorn GL, Kirklin JK, McGiffin DC, et al. A prospective algorithm for the management of air leaks after pulmonary resection. Ann Thorac Surg. 1998;66:1726-31.

4. Stéphan F, Boucheseiche S, Hollande J, Flahault A, Cheffi A, Bazelly B, et al. Pulmonary complications following lung resection: a comprehensive analysis of incidence and possible risk factors. Chest. 2000;118: 1263-70.

5. Abolhoda A, Liu D, Brooks A, Burt M. Prolonged air leak following radical upper lobectomy: an analysis of incidence and possible risk factors. Chest. 1998;113:1507-10.

6. Brunelli A, Monteverde M, Borri A, Salati M, Marasco RD, Fianchini A. Predictors of prolonged air leak after pulmonary lobectomy. Ann Thorac Surg. 2004;77:1205-10.
7. Isowa N, Hasegawa S, Bando T, Wada H. Preoperative risk factors for prolonged air leak following lobectomy or segmentectomy for primary lung cancer [letter]. Eur J Cardiothorac Surg. 2002;21:951.

8. Venuta F, Rendina EA, De Giacomo TE. Techniques to reduce air leaks after pulmonary lobectomy. Eur J Cardiothorac Surg. 1998;13:361-4.

9. Keagy BA, Lores ME, Starek PK, Murray GF, Lucas GL. Elective pulmonary lobectomy: factors associated with morbidity and operative mortality. Ann Thorac Surg. 2002;73:1727-31.

10. Droghetti A, Schiavini A, Muriana P, Comel A, De Donno G, Beccaria M, et al. Autologous blood patch in persistent air leaks after pulmonary resection. J Thorac Cardiovasc Surg. 2006;132:556-9.

11. Perelman M. Precision techniques for removal of pathological structures from the lungs. Surgery. 1983;11:12-6.

12. Craig SR, Walker WS. A proposed anatomical classification of the pulmonary fissures. J R Coll Surg Edinb. 1997;42:233-4.

13. Macchiarini P, Wain J, Almy S, Dartevelle P. Experimental and clinical evaluation of a new synthetic, absorbable sealant to reduce air leaks in thoracic operations. J Thorac Cardiovasc Surg. 1999;117:751-8.

14. Cerfolio RJ, Bass C, Katholi CR. A prospective randomized trial compares suction versus water seal for air leaks. Ann Thorac Surg. 2001; 71:1613-7.

15. Marshall MB, Deeb ME, Bleier JIS, Kucharczuk JC, Friedberg JS, Kaiser LR, et al. Suction vs water seal after pulmonary resection. A randomized prospective study. Chest. 2002;121:831-5.

16. Stolz AJ, Schutzner J, Lischke R, Simonek J, Pafko P. Predictors of prolonged air leak following pulmonary lobectomy. Eur J Cardiothor Surg. 2005;27:334-6.

17. Wong K, Goldstraw P. Effect of fibrin glue in the reduction of postthoracotomy alveolar air leak. Ann Thorac Surg. 1997;64:979-81.

18. Fleisher AG, Evans KG, Nelems B, Finley RJ. Effect of routine fibrin glue use on the duration of air leaks after lobectomy. Ann Thorac Surg. 1990;49:133-4.

19. Fabian T, Federico JA, Ponn RB. Fibrin glue in pulmonary resection: a prospective, randomized, blinded study. Ann Thorac Surg. 2003;75: 1587-92.

20. Porte HL, Jany T, Akkad R, Conti M, Gillet PA, Guidat A, et al. Randomized controlled trial of a synthetic sealant for preventing alveolar air leaks after lobectomy. Ann Thorac Surg. 2001;71:1618-22. 
21. Wain JC, Kaiser LR, Johnstone DW, Yang SC, Wright CD, Friedberg JS, et al. Trial of a novel synthetic sealant in preventing air leaks after lung resection. Ann Thorac Surg. 2001;71:1623-9.

22. Allen MS, Wood DE, Hawkinson RW, Harpole DH, McKenna RJ, Walsh GL, et al and $3 \mathrm{M} \circledast$ Surgical Sealant Study Group. Prospective randomized study evaluating a biodegradable polymeric sealant for sealing intraoperative air leaks that occur during pulmonary resection. Ann Thorac Surg. 2004;77:1792-801.

23. Thomas P, Massard G, Porte H, Doddoli C, Ducrocq X, Conti M. A new bioabsorbable sleeve for lung staple-line reinforcement (Foreseal $\left.{ }^{\circledR}\right)$ : report of a three-center phase II clinical trial. Eur J Cardiothorac Surg. 2006;29:880-5.

24. Parmar JM, Hubbard WG, Matthews H. Teflon strip pneumostasis for excision of giant emphysematous bullae. Thorax. 1987;42:144-7.

25. Hazelrigg SR, Baley TM, Naunhaim KS, Magee MJ, Henkle JQ, Keller CN. Effect of bovine pericardial strips on air leaks after stapled pulmonary resection. Ann Thorac Surg. 1997;63:1573-5.
26. Lo Cicero J III, Hartz RS, Frederikson JW, Michaelis LL. New applications of laser in pulmonary surgery: hemostasis and sealing of air leaks. Ann Thorac Surg. 1985;40:546-50.

27. Landrenau RJ, Hazelrigg SR, Johnson JA, Boley TM, Nawarewong W, Curtis TJ. Neodymium: Yttium-aluminium garnet laser assisted pulmonary resections. Ann Thorac Surg. 1991;51:973-8.

28. Verazin GT, Regal AM, Antkowiak JG, Parvez Z, Tokita H. Ultrasonic surgical aspirator for lung resection. Ann Thorac Surg. 1991;52:787-90.

29. Anegg U, Lindenmann J, Matzi V, Smolle J, Maier A, Smolle-Juttner F. Efficiency of fleece-bound sealing (Tachosil®) of air leaks in lung surgery: a prospective randomized trial. Eur J Cardiothorac Surg. 2007;31: 198-202.

30. Lang G, Csekeo A, Stamatis G, Lampl L, Hagman L, Marta GM, et al. Efficacy and safety of topical application of human fibrinogen/thrombincoated collagen patch (TachoComb) for treatment of air leakage after standard lobectomy. Eur J Cardiothorac Surg. 2004;25:160-6.

\section{ON THE MOVE?}

Don't miss a single issue of the journal! To ensure prompt service when you change your address, please photocopy and complete the form below.

Please send your change of address notification at least six weeks before your move to ensure continued service. We regret we cannot guarantee replacement of issues missed due to late notification.

\section{JOURNAL TITLE:}

Fill in the title of the journal here.

\section{OLD ADDRESS:}

Affix the address label from a recent issue of the journal here.

\section{COPY AND MAIL THIS FORM TO:}

Elsevier Inc.

Subscription Customer Service

6277 Sea Harbor Dr

Orlando, FL 32887

\section{NEW ADDRESS:}

Clearly print your new address here.

Name

Address

City/State/ZIP 